\title{
Graves' Disease Thyroid Color-Flow Doppler Ultrasonography Assessment: Review Article
}

\author{
Thiago Adler Ralho Rodrigues dos Santos, Rodrigo Otavio Gomes Pina, \\ Marina Taliberti Pereira de Souza, Maria Cristina Chammas \\ Service of Ultrasound, Department of Radiology, Hospital das Clinicas da Faculdade de Medicina da \\ Universidade de São Paulo, São Paulo, Brazil \\ Email: thiago adler@yahoo.com.br
}

Received 18 April 2014; revised 31 May 2014; accepted 15 June 2014

Copyright (C) 2014 by authors and Scientific Research Publishing Inc.

This work is licensed under the Creative Commons Attribution International License (CC BY).

http://creativecommons.org/licenses/by/4.0/

(c) (i) Open Access

\section{Abstract}

Graves' disease, as known today, is an autoimmune, diffuse, chronic disease of thyroid gland, as described by Robert Graves in 1835. It presents genetic predisposition and unknown etiology evidence, which is influenced in its development by several factors, including environment (dietary iodine intake, stress, drugs and infections). The disease is characterized by one or more changes: hyperthyroidism, goiter, ophthalmopathy, skin changes and pretibial myxedema, around $5 \%$ less common, and other symptoms $\mathbf{9 0 \%}$ to $\mathbf{9 5 \%}$. One of the most relevant clinical practice aspects in Graves' disease patients management is to distinguish Graves' disease in initial phase, from other types of destructive thyrotoxicosis, in addition to evaluate therapeutic methods and efficient follow up, as well as predict early recurrence or remission of disease. Scintigraphy with pertechnetate $(99 \mathrm{mTc})$ and TSH levels dosage are considered the choice for this purpose. However, they present some technical difficulties, as they are not widely available and have contraindications. In this scenario, thyroid color-flow doppler ultrasonography (US Doppler) presents a viable alternative, as a widely available, low cost, non-invasive and radiation free method, providing initial diagnosis and patients with Graves' disease follow up. In adittion, this method is used in differential diagnosis with other causes of thyrotoxicosis in the early stage.

\section{Keywords}

Thyroid, Graves' Disease, Ultrasonography, Color-Flow Doppler

\section{Introduction}

Graves' disease (GD), as known today, is an autoimmune, diffuse, chronic disease of thyroid gland, as described

How to cite this paper: dos Santos, T.A.R.R., Pina, R.O.G., de Souza, M.T.P. and Chammas, M.C. (2014) Graves' Disease Thyroid Color-Flow Doppler Ultrasonography Assessment: Review Article. Health, 6, 1487-1496. 
by Robert Graves in 1835 [1]. It presents genetic predisposition and unknown etiology evidence, which is influenced in its development by several factors, including environment (dietary iodine intake, stress, drugs and infections). The disease is characterized by one or more changes: hyperthyroidism, goiter, ophthalmopathy, skin changes and pretibial myxedema, around 5\% less common, and other symptoms 90 to $95 \%$.

GD, the T lymphocytes become sensitive to antigens presented in thyroid gland, and stimulate B lymphocytes to synthesize antibodies against antigens. One of these antibodies, the TSH-R Ab is aimed against the TSH membrane receptor of thyroid cells and it is able to stimulate cells function. Circulating antibody is associated with disease positivity and recurrence.

This pathology incidence is higher in women (around 5 - 10:1) [2] [3], clearly in any age, although 20 - 40 years old more often. It is common in Caucasians and Asians, compared to blacks [4].

Pregnancy, excess iodine intake in certain regions, viral or bacterial infection, corticosteroids suspension, lithium treatment (alters immune system), are some factors that can stimulate immune response in GD.

Treatment options for hyperthyroidism caused by GD are: antithyroid drugs (tapazole, metimazol and propylhtiouracil), radioiodine $\left({ }^{131} \mathrm{I}\right)$ and, the last resort, surgery [3] [5]. The three treatments are effective, nevertheless, present problems and/or side effects, and none offers, an absolute cure for the disease.

One of the most relevant clinical practice, aspects in GD patients management is to distinguish GD in initial phase, from other types of destructive thyrotoxicosis, in addition to evaluate therapeutic methods and efficient follow up, as well as predict early recurrence or remission of disease. Scintigraphy with pertechnetate $\left({ }^{99 m} \mathrm{Tc}\right)$ and TSH levels dosage are considered the choice for this purpose. However, they present some technical difficulties, as they are not widely available and have contraindications [6] [7].

In this scenario, thyroid color-flow doppler ultrasonography (US Doppler) presents a viable alternative, as a widely available, low cost, non-invasive and radiation free method, providing initial diagnosis and patients with GD follow up. In addition, this method is used in differential diagnosis with other causes of thyrotoxicosis in the early stage [6]-[10].

\section{Clinical and Laboratorial Diagnosis}

Laboratorial exams in GD diagnosis include serum dosage of hormones and antibodies, such as total T4, free T4, TSH and T3 levels, TSH receptor antibody (TRAb), anti-thyroperoxidase (TPO) and thyroblobulin (Tg) routinely, which parallel to clinical examination are essential in patient's evaluation.

TRAb level among these laboratorial exams, perhaps, is the most important in patients propaedeutic, as it provides diagnosis in early stages of disease, when symptoms are not exuberant, making it hard to distinguish GD from other thyrotoxicosis due to thyroiditis, and in the differential diagnosis between transient gestational thyrotoxicosis and GD during pregnancy [11].

It is one of the most important differentiation and must be done earlier, because the therapeutic management of thyrotoxicosis caused by the DG and thyroiditis are different. Thyroditis is auto limited and treated only symptomatic. On the other hand, antithyroid drugs, surgery or radioiodine therapy is necessary in GD [7] [8] [12] [13].

\section{Ultrasonography Diagnosis}

Thyroid Doppler US has gained an important role in initial study and GD follow up. Thyroid gland ultrasound examination performed in high frequency equipment (over $10 \mathrm{MHz}$ ) and by an experienced operator is able to identify easily the presence of focal and diffuse disease, rendering diagnosis of early alterations in the gland. Assessment is at the same time qualitative (gland visual vascularization impression) and quantitative (superior or inferior thyroid arteries peak systolic velocity) [6] [8] [10] (Figure 1).

Exam technique is the fundamental importance and must be always followed in order to obtain the correct gland evaluation with good reproducibility. The study must be done with the patient laying down, cervical hyperextension, and a pillow under the shoulders. The transducer must be lightly placed over the skin, without compression, so that vascularization is not underestimated. A water based gel must be used for simple skin transducer adherence. No prior preparation is required.

The ultrasound scanner must be adjusted to gland for correct evaluation following specific thyroid protocol, according to parameters: Map 3; Persist Low; 2D Opt: Res and Dynamic Rage: 90. As for the color Doppler pattern and amplitude, use the following: velocity scale $\leq 5.0 \mathrm{~cm} / \mathrm{s}$ (PRF em $700 \mathrm{~Hz}$ ); Map 1; WF Med; Flow Opt: 

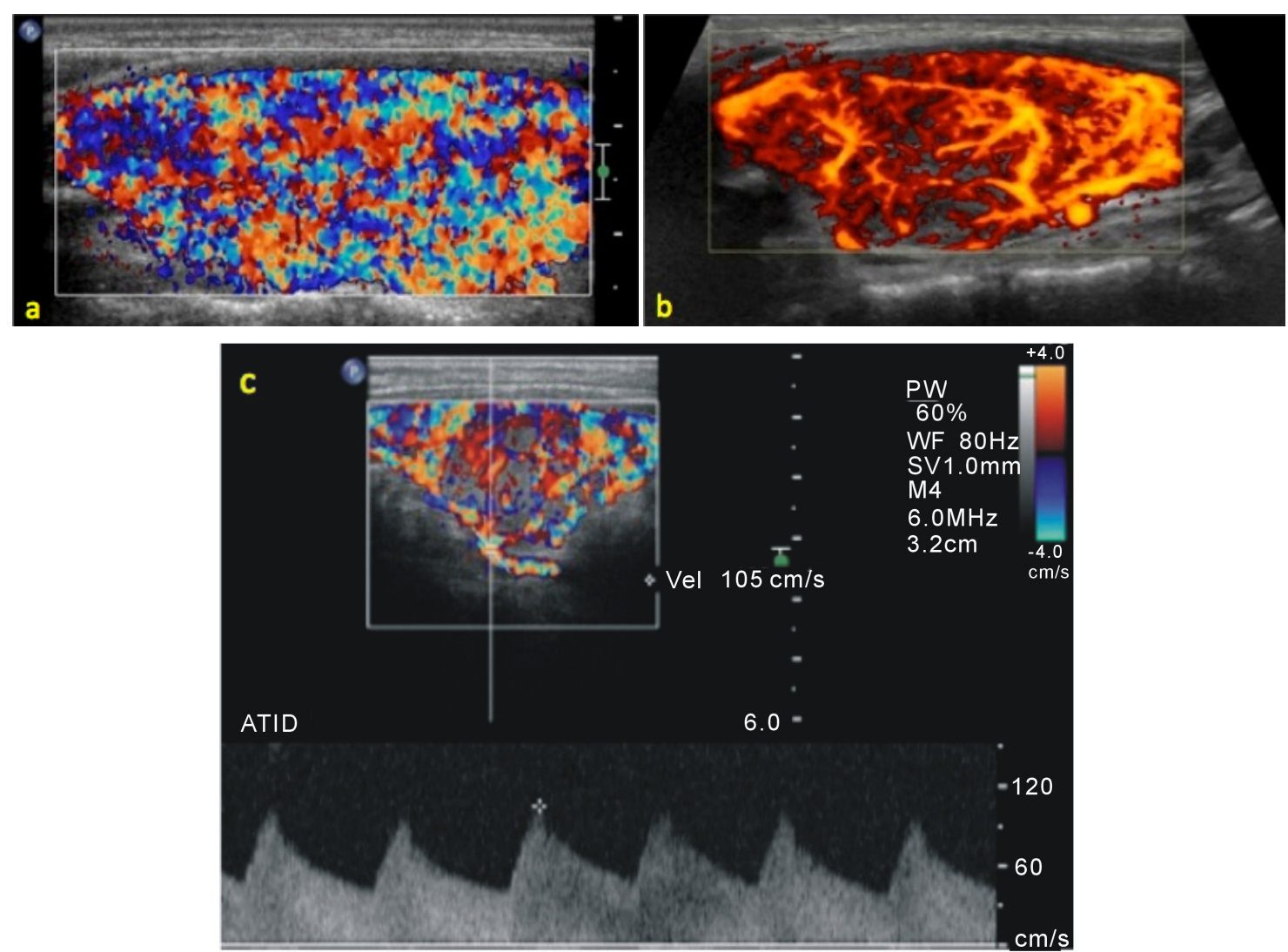

Figure 1. Qualitative (gland visual vascularization impression) and quantitative (thyroid arteries peak systolic velocity) assessment of thyroid gland. Diffuse increase of the parenchyma vascularization, known as "thyroid inferno", in color Doppler (a) and power Doppler (b), before GD treatment or effective therapy. Measurement of right inferior thyroid artery peak systolic velocity in spectral analysis (c), demonstrating the increased speed in patients with GD not treated or not responsive to treatment.

\section{Med V (Figure 2).}

Also high frequencies (>10 MHz) broadband linear array transducer and a convex transducer of $2-5 \mathrm{MHz}$ and/or panoramic reconstruction to measure the thyroid gland in large goiters.

\section{B Mode Evaluation}

We should evaluate GD, in B mode, the gland dimension (volume) and diffuse thyroid parenchyma alterations. Although, focal lesions occurrence (nodules) is unusual in GD, whenever they are found, they should be evaluated according to their features by B mode and collor Doppler, and further investigated by fine-needle aspiration biopsy (FNAB), as indicated.

\subsection{Gland Volumetry}

Gland dimensions are usually enlarged, with global gland volume above normality, 6 to $15 \mathrm{~cm}^{3}(10-11+3-4$ $\mathrm{cm}^{3}$ ) [14]. In many cases, patients with GD are diagnosed and, consequently treated, when presenting large goiters, sometimes plunging, causing compression/deviation of adjacent structures such as trachea, esophagus and vascular structures, leading to dyspnea and dysphagia, and also, aesthetic discomfort to the patient. In a study developed by Macedo, at Hospital das Clínicas-FMUSP, Ultrasound Radiology Institute, Macedo found normal adult thyroid values $13.05 \pm 5.67 \mathrm{ml}$, with no gender distinction in the given population [15].

The thyroid gland correct volume should be obtained by maximum measures in the longitudinal (L), anteroposterior (AP) and transverse (T) axis of both lobes and isthmus. The volume (TV) the elipse correction coefficient used is (TV $=\mathrm{L} \times \mathrm{AP} \times \mathrm{T} \times \pi / 6)$ (Figure 3). The lobes and isthmus volumes are added to obtain the total 

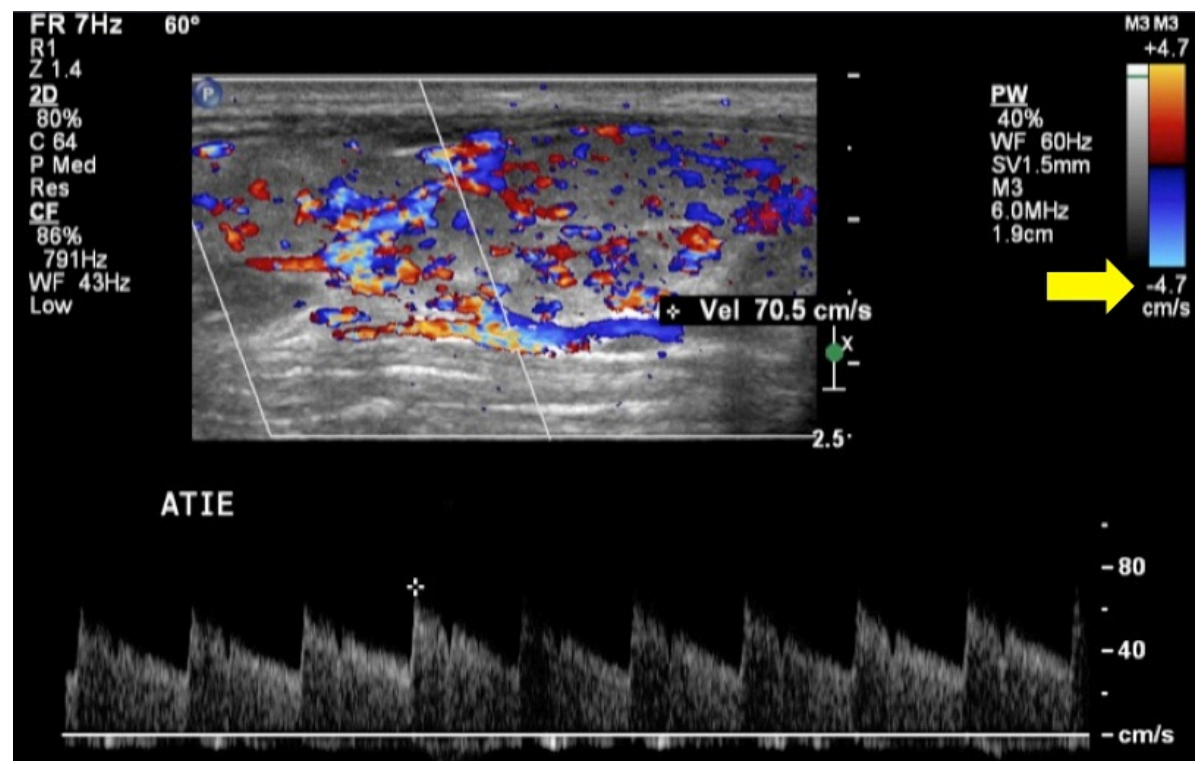

Figure 2. Ultrasound scanner must be adjusted to gland for correct evaluation following specific thyroid protocol. Special attention to the velocity scale that must always be equal or less than $5.0 \mathrm{~cm} / \mathrm{s}$, to thyroid arteries systolic peak velocity measurement.

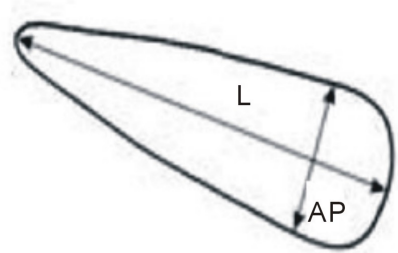

Corte longitudinal

LD/I/LE

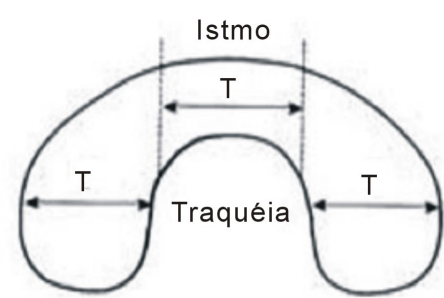

LD

Figure 3. Scheme demonstrating how thyroid lobes should be measured in the longitudinal and transverse axis (Image taken from Chammas, M.C., Saito, O.C. and Cerri, C.C. (1999) Tireoide. In: Saito, O.C. and Cerri, G.G., Eds., Ultra-Songorafia Pequenas Partes, 1a. Ed., Savier, São Paulo, 14-55) [25].

gland volume. The anteroposterior axis is one of the measures that could be questioned; in fact, it does not matter if it is done in the longitudinal or gland transverse measure once greater extent is considered.

Considering, isthmus measure, whenever its extension or boundaries cannot be assessed with the lobes in the transversal axis, the trachea projection could be used. It is important to point out that high transducer frequency, fine delimitation can be easily identified between lobes and isthmus. In GD patients, the isthmus volume is considerably enlarged and cannot be excluded from the total gland volume calculation, because it can influence, for example, in the radioiodine calculation dose to be administered to the patient, resulting in subdose.

A common mistake in gland volumetric measure is the lobe estimated size in the longitudinal axis. To avoid errors, we should attend to lobe poles measurement inclusion.

Much more attention should be taken when the lobe is wide, so that the lobe dimension and not the transducer is considered (when one of the thyroid poles is out of the picture, the lobe image is cut off, and what you are measuring is the transducer size and not the lobe).

Lobe size also should not be estimated, moving the cursor outside the image and taking an imaginary lobe measure. A lower frequency transducer can be used to avoid this type of error and provide a better scope image (convex or endocavitary transducer) (Figure 4), or composing the image with a linear transducer, or creating an 

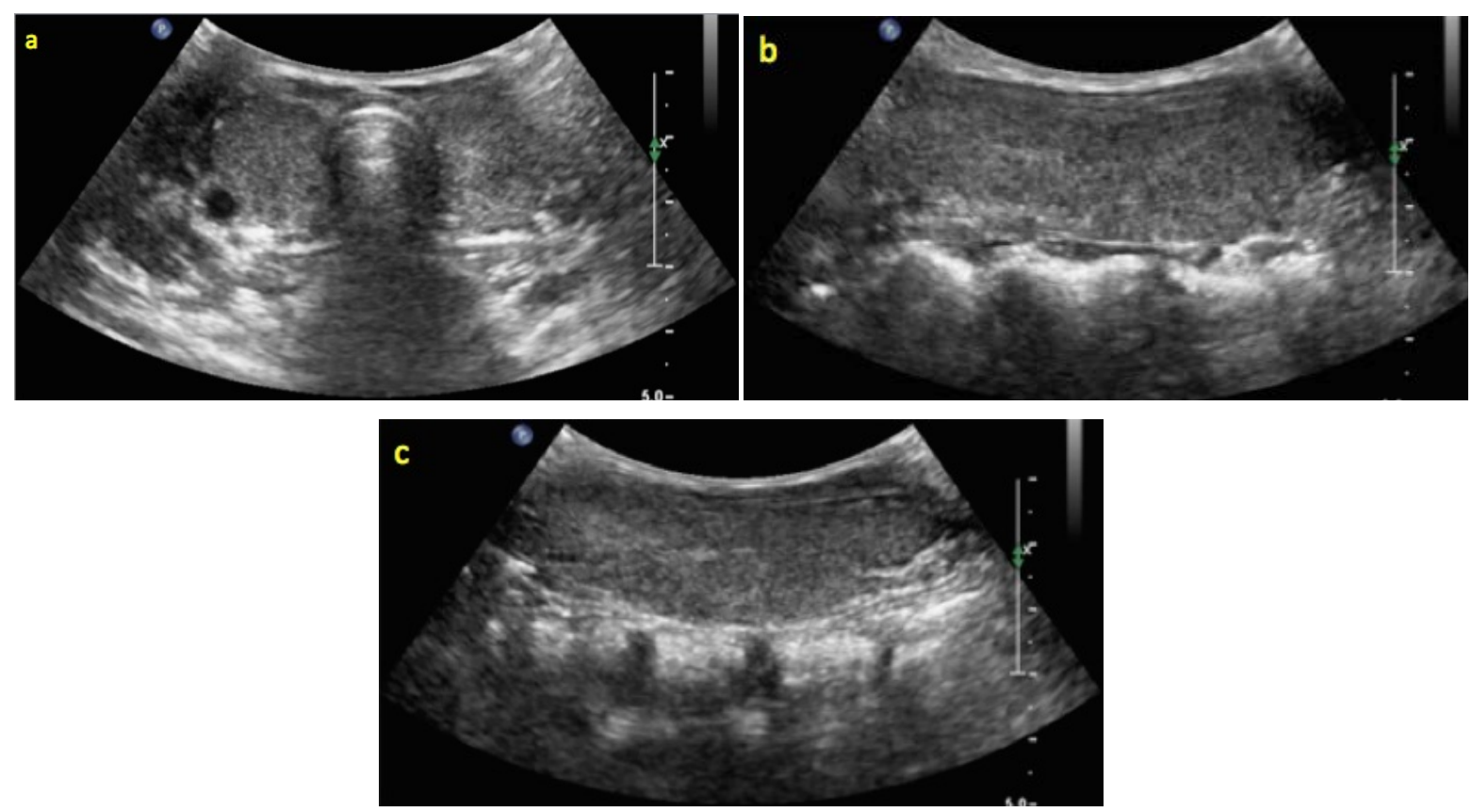

Figure 4. A lower frequency transducer can be used to provide a better scope image (convex transducer) in patients with GD when presenting large goiters. The image shows the transverse axis of the thyroid (a), longitudinal axis of the right lobe (b) and longitudinal axis of the left lobe (c).

extended image (panoramic) or even, using a trapezoidal option in the linear transducer. This way thyroid volume underestimates which measure could be avoided, and lead to inappropriate treatment, especially in radioiodine dose calculation, based on the volume, as previously mentioned.

\subsection{Parenchyma Changes}

Thyroid ultrasonography clinical practice introduction occurred in the late sixties, resulting in fast evolution development with more sensitive high frequency and high resolution transducers, proving gland effectiveness and its pathologies [16].

Normal gland has an echogenicity characteristic in ultrasound, easily distinguishable from adjacent muscular structures. The thyroid gland ecogenicity is due to its follicular structure: the interface among thyroid cells and colloid produces high acoustic impedancy, causing high frequency sound waves to be reflected back to the probe [16]. Resulting greater ecogenicity relative to the neck muscles and bigger or equal to the submandibular glands, so it is very important to compare the gland correctly and classified in isoechogenic, hipoechogenic or hiperechogenic (Figure 5).

Conditions that change the normal anatomic gland structure such as thyroid autoimmune diseases, can lead to an echographic aspect which vary from parenchyma subtle changes to characteristic features, that include diffuse heterogeneity and hypoechogenicity, with dense fibrotic beams permeating (Figure 6). Keep in mind that $90 \%$ of the time, hypoechogenic glands are due to autoimmune diseases, and in GD, hypoechogenicity is a result of hypervascularity and hypercellularity [17].

Vitti et al. [18] proved that in a study group including 105 patients, 70\% of GD patients showed low thyroid gland echogenicity. This pattern is related to TRAb higher positive frequency and hyperthyroidism recurrence.

\section{Color and Spectral Doppler Ultrasonography}

\subsection{Color Doppler}

Color Doppler evaluation is GD ultrasonography diagnosis' next step, and probably the most important. It is important to use the proper technique in color Doppler study (transducer pressure over skin should be minimum), the appropriate transducer and equipment adjustment (velocity scale should be maintained with values $\leq 5.0$ 

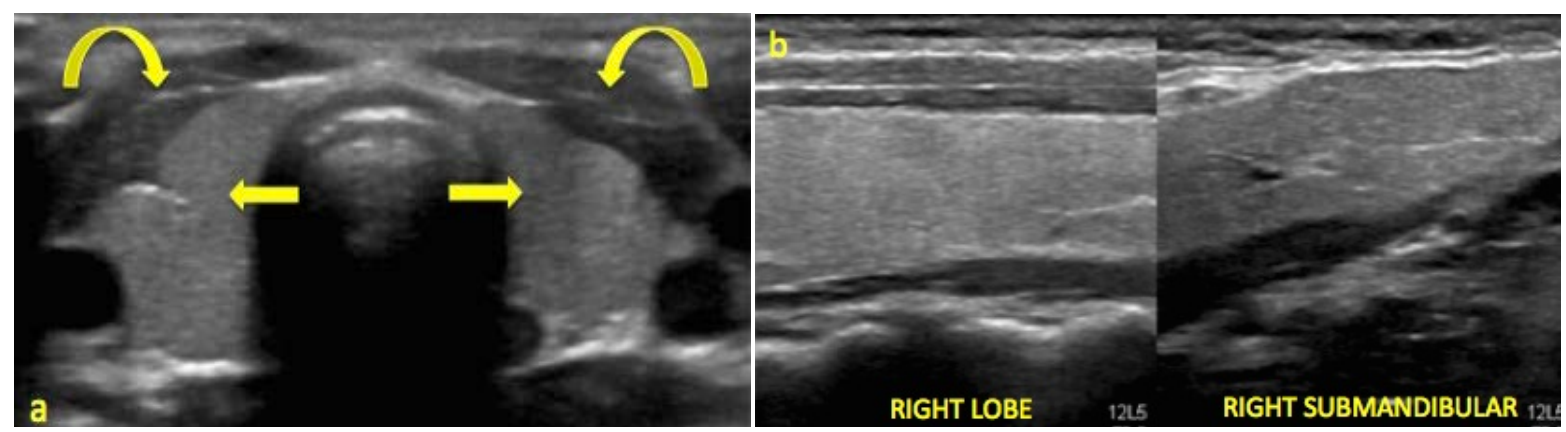

Figure 5. Normal gland has an echogenicity characteristic in ultrasound, easily distinguishable from adjacent muscular structures. Notice in figure (a) greater ecogenicity in thyroid (straight arrow) relative to the neck muscles (curved arrow) and, in figure (b) bigger or equal to the submandibular glands.
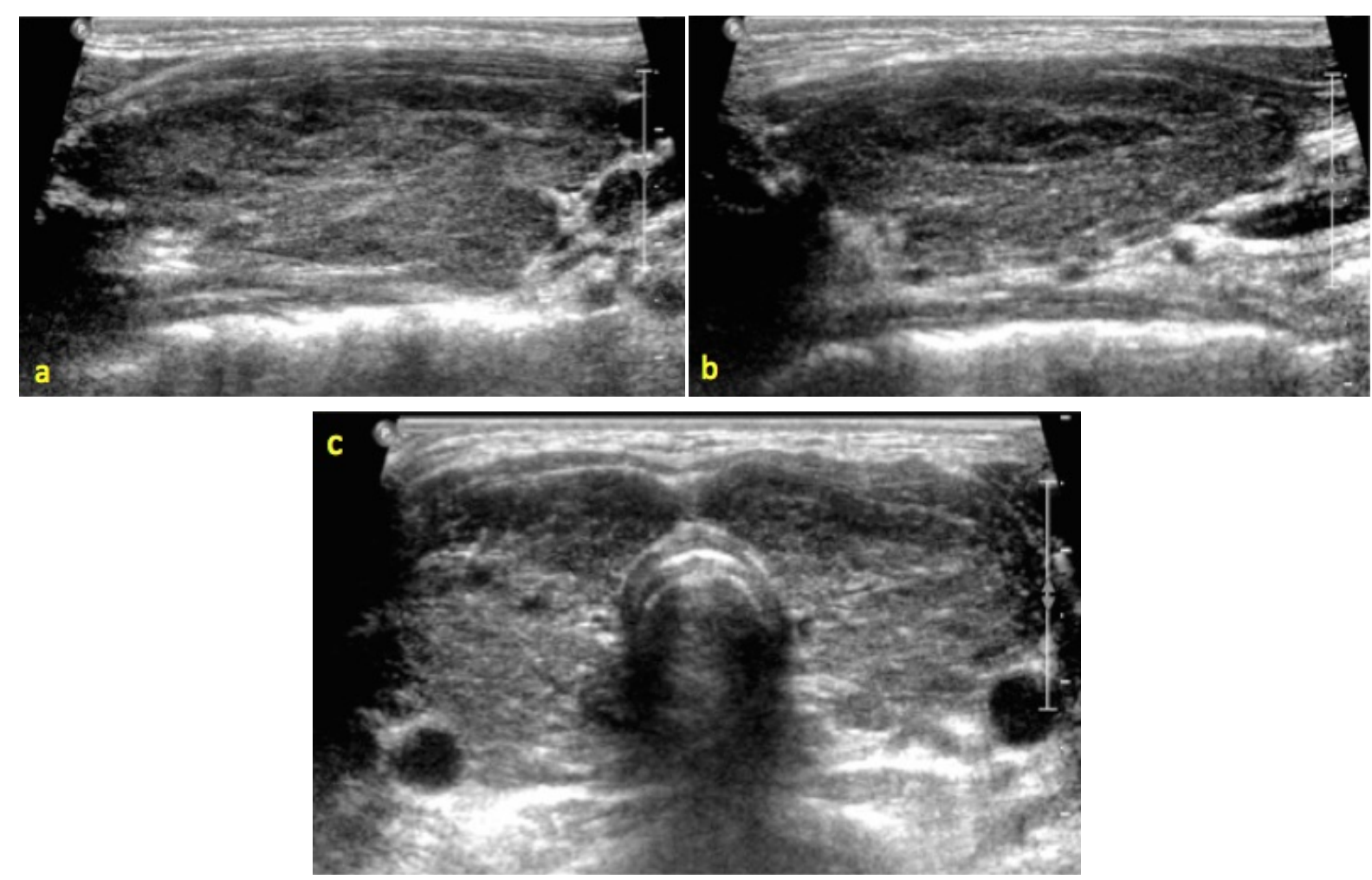

Figure 6. Changes to the characteristic features of normal gland, in GD are seen to B mode sonographic. Diffuse heterogeneity and hypoechogenicity, with dense fibrotic beams permeating in the longitudinal axis of the right lobe (a), longitudinal axis of the left lobe (b) and transverse axis of the thyroid (c).

cm/s). According to North America Radiological Society (RSNA) recommendations, Doppler mapping should be made by sensitive equipment and a trained operator.

Before GD treatment or effective therapy, there is a diffuse increase of the parenchyma vascularization, known as "thyroid inferno" (Figure 7), a term first used to describe this phenomenon in Ralls et al. [19] publication, in 1988. Thyroid hypervascularization can also occur in thyroiditis, but at a lesser level.

The thyroid gland vascularization correlates to the underlying functional status, decreases with the disease under control and can rise again in cases of recurrence. Many authors, observed that GD vascularity decrease occurred in parallel to the biochemistry remission and disease control, ratifying that thyroid US Doppler has the potential to monitor therapy response in patients with GD, as well as distinguish GD patients from Hashimoto thyroiditis, with similar B-mode pattern, without the use of expensive laboratory assays [6]-[13] [19] [20] in their studies. 

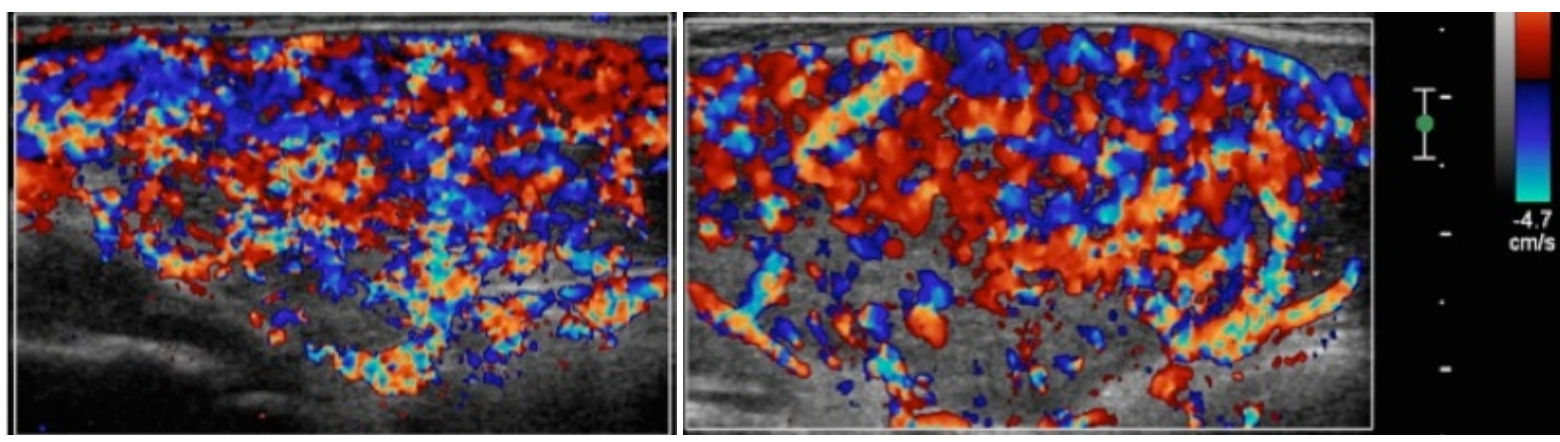

Figure 7. Color Doppler demonstrating a diffuse increase of the parenchyma vascularization, known as "thyroid inferno”.

\subsection{Spectral Analysis}

Thyroid arteries systolic peak velocity (SPV) measurement is done $1 \mathrm{~mm}$ sample volume adjustment, in vessel centre, the insonation angle should be $0^{\circ}-60^{\circ}$ and correction angle adjusted parallel to the vessel wall [6] [12] [13] (Figure 8). The SPV can be measured in the inferior or the superior thyroid arteries. There is no significant difference between the SPV in the inferior thyroid artery gland of both sides [10]. Also, there is no significant difference between the superior or inferior thyroid arteries measurement.

Inferior thyroid arteries measurement is used in our institution, once they are thyrocervical trunk tributaries, and less influenced by the blood supply than the external carotid arteries (superior thyroid arteries tributaries), once they can have their values changed by external carotid stenosis. The inferior thyroid arteries are seen crossing the common carotid arteries posteriorly in the transversal axis, or in the longitudinal scan, the ascending parts of the arteries are seen in parallel to the common carotid arteries [6] [8] [11].

Macedo's study et al. [21], with US Doppler reference values in 84 healthy subjects without iodine deficiency, the normal SPV obtained was $24.80 \mathrm{~cm} / \mathrm{s}$ and $25.85 \mathrm{~cm} / \mathrm{s}$ in the superior thyroid arteries and $20.92 \mathrm{~cm} / \mathrm{s}$ and $21.50 \mathrm{~cm} / \mathrm{s}$ in the inferior thyroid arteries.

Donkol et al. [8] considered the systolic peak velocity $40.0 \mathrm{~cm} / \mathrm{s}$ in the inferior thyroid artery as higher and suggestive to GD, while most authors consider the velocity value above $50.0 \mathrm{~cm} / \mathrm{s}$ for patients with this disease, values above $100.0 \mathrm{~cm} / \mathrm{s}$ (Figure 9) can be reached and not treated or not responsive to treatment [10] [13].

In our experience, a cut off $50.0 \mathrm{~cm} / \mathrm{s}$ velocity is considered to GD diagnosis measurement in the inferior thyroid arteries, and we could verify that patients responded to the treatment, with drugs or radioiodine, presented with SPV reduction, while the parenchyma vascularity, although showing a significative reduction, remains increased when compared to the normal gland. In non-treated patients or non-responsive to the treatment no SPV decreasing is noted, so then US Doppler entitles is an excellent patient management method.

Thyroid arteries SPV method has become accurate and reliable, with excellent reproducibility [6] [7] [9] [13] in modern advanced technology. Therefore, in GD analysis, thyroid arteries velocity measurement (superior and/or inferior) is indispensable.

\section{Thyrotoxicosis Types Ultrasonography Differentiation}

The thyrotoxicosis clinical manifestations in thyroiditis and mild or initial GD can be difficult to differentiate. The US Doppler provides important support in this etiologic differentiation, notedly to diffuse toxic goiter, that can be originated by destructive thyroiditis resultant from several causes or GD [6] [7] [12].

In 1995, Vitti e col [20] demonstrated that the thyroid blood flow can be correlated to the thyroid state in patients with GD, being significantly increased in 17/18 patients with non-treated active hyperthyroidism and less clearly increased in treated patients. In patients with Hashimoto thyroiditis, the thyroid blood flow did not correlate to the functional state of the gland [6] [20].

Kurita et al. [22], after studying 75 patients with thyrotoxicosis, demonstrated $84 \%$ sensitivity and $90 \%$ specificity of US Doppler in the differential diagnosis types of thyrotoxicosis. Kumar et al. [10] also showed similar sensitivity and specitivity. Therefore, results where comparable to nuclear image (90\% sensitivity and $90 \%$ specificity) in GD diagnosis.

Zhao et al. [13] performed two studies, simultaneously, one retrospective with 135 patients, from 2006 to 


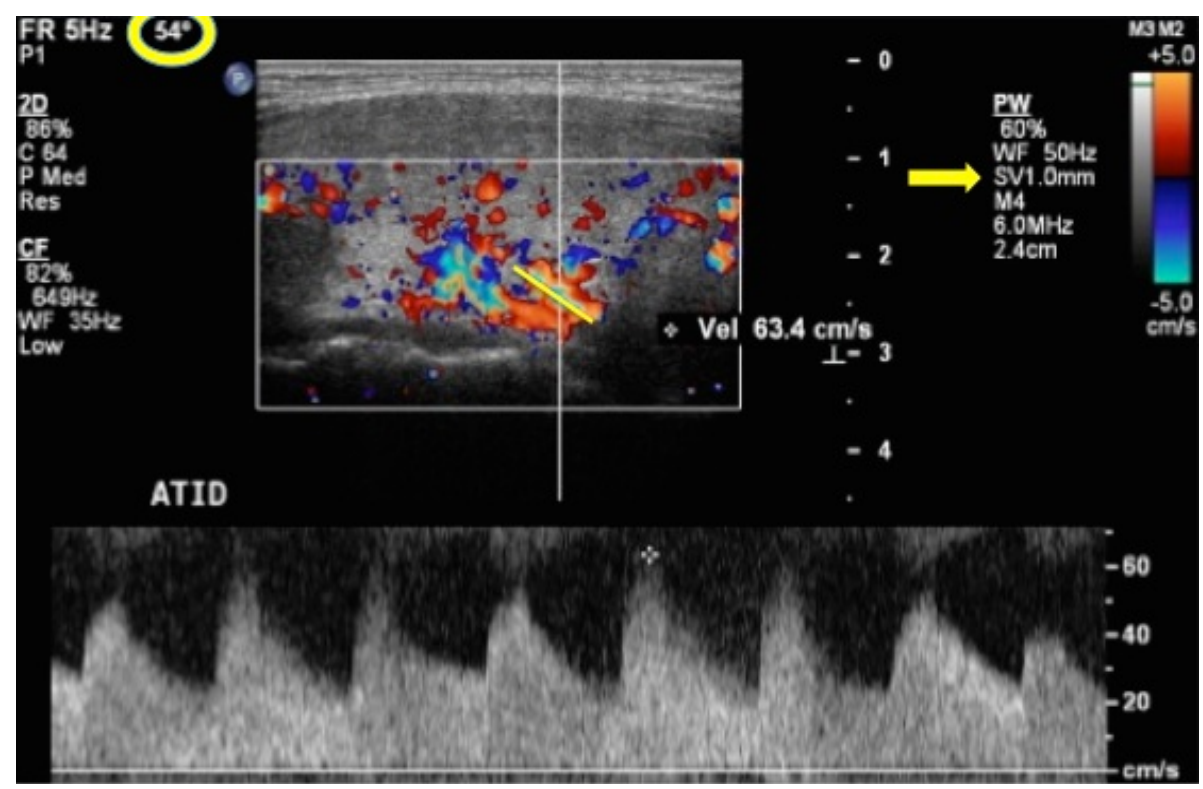

Figure 8. Thyroid arteries systolic peak velocity measurement is done $1 \mathrm{~mm}$ sample volume adjustment, in vessel centre, the insonation angle shoud be $0^{\circ}-60^{\circ}$ and correction angle adjusted parallel to the vessel wall.
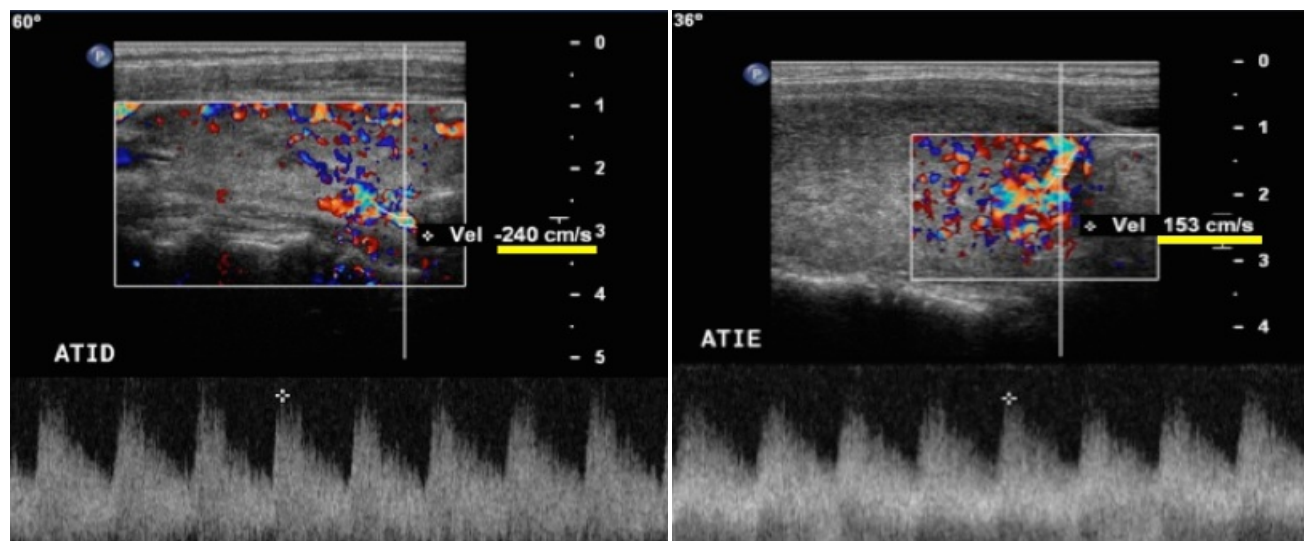

Figure 9. Systolic peak velocity above $100 \mathrm{~cm} / \mathrm{s}$ in the inferior thyroid artery, can be reached for patients with Graves' disease not treated or not responsive to treatment.

2009, and another prospective with 169 patients, 2009 to 2011, both obtained a cut off $50.0 \mathrm{~cm} / \mathrm{s}$ velocity in the systolic peak in the superior thyroid arteries, creating an excellent value in thyroiditis and GD differentiation. They obtained a good reproducibility assay [13].

Donkol et al. [8], in a study published in 2013, confirmed that the spectral analysis of the velocity flow in the inferior thyroid arteries was significantly increased in patients with GD than in patients with destructive thyroiditis. However, the cut-off value of maximum systolic velocity was considered $40.0 \mathrm{~cm} / \mathrm{s}$, which was significant in differentiating GD and thyroiditis [8].

Based in the data exposed, it becomes clear that SPV is a practical method, accurate and reliable in the differrential diagnosis of thyrotoxicosis, that can be used in daily routine, especially when radioiodine uptake is contraindicated during pregnancy and lactation [6] [7] [12] [13].

\section{Comparison with Other Methods}

Thyroid scintigraphy and uptake are definitive diagnosis tools, especially when there is clinical confusion among thyrotoxicosis causes. However, limited availability, high cost and radioisotopes exams not recommended dur- 


\begin{tabular}{|c|c|c|c|}
\hline & NORMAL THYROID & THYROIDITIS & GRAVES' DISEASE \\
\hline GLAND VOLUMETRY & $6-15 \mathrm{~cm}^{3}$ & Decreased, normal or increased (goiter) & Increased (goiter) \\
\hline ECOGENICITY & $\begin{array}{l}\text { Bigger or equal to the } \\
\text { submandibular glands }\end{array}$ & $\begin{array}{l}\text { Isoechogenic or } \\
\text { Hypoechogenic }\end{array}$ & Hypoechogenic \\
\hline TEXTURE & Homogeneous & $\begin{array}{c}\text { Diffuse heterogeneity, may be } \\
\text { hypoechogenic areaspermeating } \\
\text { (lymphocytic infiltrates) and/or } \\
\text { hyperechogenic lines (dense fibrotic } \\
\text { beams) }\end{array}$ & $\begin{array}{l}\text { Diffuse heterogeneity may be } \\
\text { hyperechogenic lines (dense } \\
\text { fibrotic beams) }\end{array}$ \\
\hline $\begin{array}{c}\text { PARENCHYMA } \\
\text { VASCULARIZATION }\end{array}$ & $\begin{array}{l}\text { Few vessels scattered by the } \\
\text { middle third of the glandular } \\
\text { parenchyma and vessels in the } \\
\text { periphery of the gland }\end{array}$ & $\begin{array}{l}\text { Reduced, normal orincreased (less } \\
\text { intense than inGraves' disease) }\end{array}$ & $\begin{array}{c}\text { Diffuse increase ("thyroid } \\
\text { inferno") }\end{array}$ \\
\hline SPV & $<40 \mathrm{~cm} / \mathrm{s}$ & Usually $<40 \mathrm{~cm} / \mathrm{s}$ & $>50 \mathrm{~cm} / \mathrm{s}$ \\
\hline
\end{tabular}

Figure 10. Comparative table of sonographic findings in the normal thyroid gland, in thyroiditis and in Graves' disease.

ing pregnancy and breastfeeding can limit the use [6] [7]. Besides these tests cannot be done in many patients after use of iodinated contrast for other diagnostic studies such as computed tomography (CT), interfering with radioiodine tests accuracy. Phillips et al. [23] found, in his studies, that $45 \%$ thyrotoxicosis patients newly diagnosed had received iodinated contrast within 2 weeks from the endocrinological evaluation, $43 \%$ had received iodine for CT and the other $2 \%$ for angiography.

Donkol et al. [8] study, in 26 patients with thyrotoxicosis, a pertechnetate scintigraphy was used as a definitive method to differentiate patients with two types of thyrotoxicosis (GD and Hashimoto thyroiditis) and US Doppler as another parameter to differentiate the two types of thyrotoxicosis and compare sensitivity and specificity with ${ }^{99 \mathrm{~m}}$ Tc scintigraphy. US Doppler demonstrated sensitivity of $88.9 \%$ and specificity of $87.5 \%$, positive predictive value of $94.1 \%$, negative predictive value of $77.8 \%$ and diagnostic accuracy of $88.5 \%$, in the differential diagnosis of the two thyrotoxicosis compared to ${ }^{99 \mathrm{~m}}$ Tc scintigraphy [8].

The results corroborate to Kurita's findings et al. [22], observing sensitivity of $84 \%$ and specificity of $90 \%$ in thyrotoxicosis differential diagnosis, as well as Kumar's et al. [24] sensitivity of 96\% and specificity of 95\% in this distinction.

\section{Conclusions}

Thyroid gland assessment in GD should be multifactorial, considering B-mode, color Doppler and spectral Doppler features.

The characteristics of the ultrasound are very important for diagnosis of GD and follow up in order to assist the physician during therapy. The ultrasound study pathology diagnostic criteria is the glandular volume increase, heterogeneity and parenchyma hypoechogenicity, diffuse increase in parenchyma vascularity and marked thyroid arteries velocity increase (Figure 10).

Thus, US Doppler is an excellent alternative to radioisotopes exams, with similar accuracy and without contraindication.

\section{References}

[1] Graves, R.J. (1835) Newly Observed Affection of the Thyroid. London Medical and Surgical Journal, 7, 515.

[2] Weetman, A.P. (2000) Graves’ Disease. The New England Journal of Medicine, 343, 1236-1248. http://dx.doi.org/10.1056/NEJM200010263431707

[3] Vieira, L.O., Kubo, R., Sapienza, M.T., Willegaignon, J., Chammas, M.C., Coura-Filho, G.B., Ono, C.R., Watanabe, T., Sado, H.N. and Buchpiguel, C.A. (2011) Correlação entre Volume Tireoidiano Determinado pelo Método de Ultrassonografia Versus Cintilografia e sua Implicação em Cálculos Dosimétricos na Terapia com Radioiodo na Doença de Graves. Arquivos Brasileiros de Endocrinologia \& Metabologia, 55, 9. http://dx.doi.org/10.1590/S0004-27302011000900005

[4] Davies, T.F. (1992) New Thinking on the Immunology of Graves’ Disease. Thyroid Today, 15, 1-11.

[5] Andrade, V.A., Gross, J.L. and Maia, A.L. (2001) Tratamento do Hipertiroidismo da Doença de Graves. Arquivos Brasileiros de Endocrinologia \& Metabologia, 45, 609-618. http://dx.doi.org/10.1590/S0004-27302001000600014 
[6] Zuhur, S.S., Ozel, A., Kuzu, I., Erol, R.S., Ozcan, N.D., Okcan, B., Yenici, F.U. and Altuntas, Y. (2013) The Diagnostic Utility of Color Doppler Ultrasonography, Tc-99m Pertechnetate Uptake and TSH Receptor Antibody for Differential Diagnosis between Graves’ Disease and Silent Thyroiditis: A Comparative Study. Subject Health Services, Medical Sciences and Endocrinology, 20, 310-319.

[7] Chen, L., Zhao, X., Liu, H., Wang, Y., Li, L., Lu, B., Li, Y. and Hu, R. (2012) Mean Peak Systolic Velocity of the Superior Thyroid Artery Is Correlated with Radioactive Iodine Uptake in Untreated Thyrotoxicosis. Journal of International Medical Research, 40, 640-647. http://dx.doi.org/10.1177/147323001204000226

[8] Donkol, R.H., Nada, A.M. and Boughattas, S. (2013) Role of Color Doppler in Differentiation of Graves’ Disease and Thyroiditis in Thyrotoxicosis. World Journal of Radiology, 5, 178-183.

[9] Alzahrani, A.S., Ceresini, G. and Aldasouqui, S.A. (2012) Role of Ultrasonography in the Differential Diagnosis of Thyrotoxocosis: A Noninvasive, Cost-Effective, and Widely Available but Underutilized Diagnostic Tool. Endocrine Practice, 18, 567-578. http://dx.doi.org/10.4158/EP11170.RA

[10] Hari Kumar, K.V.S., Vamsikrishna, P., Verma, A., Muthukrishnan, J., Ramasubba Rayudu, B. and Modi, K.D. (2009) Utility of Colour Doppler Sonography in Patients with Graves’ Disease. West Indian Medical Journal, 58, 566-570.

[11] Zuhur, S.S., Özel, A., Velet, S., Bugdacı, M.S., Çil, E. and Altuntas, Y. (2012) Is the Measurement of Inferior Thyroid Artery Blood Flow Velocity by Color-flow Doppler Ultrasonography Useful for Differential Diagnosis between Gestational Transient Thyrotoxicosis and Graves’ Disease? A Prospective Study. Clinics, 67, 125-129. http://dx.doi.org/10.6061/clinics/2012(02)06

[12] Karakas, O., Karakas, E., Cullu, N., Demir, Y., Kucukyavas, Y., Surucu, E., Yener, S. and Igci, E. (2014) An Evaluation of Thyrotoxic Autoimmune Thyroiditis Patients with Triplex Doppler Ultrasonography. Clinical Imaging, 38, 1-5. http://dx.doi.org/10.1016/j.clinimag.2013.06.010

[13] Zhao, X., Chen, L., Li, L., Wang, Y., Wang, Y., et al. (2012) Peak Systolic Velocity of Superior Thyroid Artery for the Differential Diagnosis of Thyrotoxicosis. PLOS ONE, 7, Article ID: e50051. http://dx.doi.org/10.1371/journal.pone.0050051

[14] Solbiati, L., Rizzatto, G. and Charboneau, J.W. (1995) Ultrasound of Superficial Structures-High Frequencies, Doppler and Interventional Procedures. Churchill Livingstone, New York.

[15] Macedo, T.A.A. (2006) Distinção entre os Tipos 1 e 2 de Tireotoxicose Associada à Amiodarona por Meio de DúplexDoppler Colorido. Doutorado, Universidade de São Paulo, São Paulo.

[16] Vitti, P. (2000) Grey Scale Thyroid Ultrasonography in the Evaluation of Patients with Graves’ Disease. European Journal of Endocrinology, 142, 22-24. http://dx.doi.org/10.1530/eje.0.1420022

[17] Höfling, D.B., Cerri, G.G., Juliano, A.G., Marui, S. and Chammas, M.C. (2008) Value of Thyroid Echogenicity in the Diagnosis of Chronic Autoimmune Thyroiditis. Radiologia Brasileira, 41, 409-417.

[18] Vitti, P., Rago, T., Mancusi, F., Pallini, S., Tonacchera, M., Santini, F., et al. (1992) Thyroid Hypoechogenic Pattern at Ultrasonography as a Tool for Predicting Recurrence of Hyperthyroidism after Medical Treatment in Patients with Graves’ Disease. Acta Endocrinologica, 126, 128-131.

[19] Ralls, P.W., Mayekawa, D.S., Lee, K.P., Colletti, P.M., Radin, D.R., Bosnell, W.D., et al. (1988) Color-Flow Doppler Sonography in Graves’ Disease: “Thyroid Inferno”. American Journal of Roentgenology, 150, 781-784. http://dx.doi.org/10.2214/ajr.150.4.781

[20] Vitti, P., Rago, T., Mazzeo, S., et al. (1995) Thyroid Blood Flow Evaluation by Color-Flow Doppler Sonography Distinguishes Graves’ Disease from Hashimoto’s Thyroiditis. Journal of Endocrinological Investigation, 18, 857-862. http://dx.doi.org/10.1007/BF03349833

[21] Macedo, T.A., Chammas, M.C., Jorge, P.T., Pereira de Souza, L., Farage, L., Pegoraro, B.L., Pessa, S.U. and Cerri, G.G. (2007) Reference Values for Doppler Ultrasound Parameters of the Thyroid in a Healthy Iodine-Non-Deficient Population. The British Journal of Radiology, 80, 625-630. http://dx.doi.org/10.1259/bjr/69016171

[22] Kurita, S., Sakurai, M., Kita, Y., Ota, T. and Ando, H. (2005) Measurement of Thyroidal Blood Flow Area Is Useful for Diagnosing the Cause of Thyrotoxicosis. Thyroid, 11, 1249-1252. http://dx.doi.org/10.1089/thy.2005.15.1249

[23] Phillips, B.D. and Hennessey, J.V. (2009) Iodinated Contrast Prior to Evaluation for Thyrotoxicosis. Journal of Hospital Medicine, 4, 285-288. http://dx.doi.org/10.1002/jhm.384

[24] Hari Kumar, K.V., Pasupuleti, V., Jayaraman, M., Abhyuday, V., Rayudu, B.R. and Modi, K.D. (2009) Role of Thyroid Doppler in Differential Diagnosis of Thyrotoxicosis. Endocrine Practice, 15, 6-9. http://dx.doi.org/10.4158/EP.15.1.6

[25] Chammas, M.C., Saito, O.C. and Cerri, C.C. (1999) Tireoide. In: Saito, O.C. and Cerri, G.G., Eds., Ultra-Songorafia Pequenas Partes, Savier, São Paulo, 14-55. 
Scientific Research Publishing (SCIRP) is one of the largest Open Access journal publishers. It is currently publishing more than 200 open access, online, peer-reviewed journals covering a wide range of academic disciplines. SCIRP serves the worldwide academic communities and contributes to the progress and application of science with its publication.

Other selected journals from SCIRP are listed as below. Submit your manuscript to us via either submit@scirp.org or Online Submission Portal.
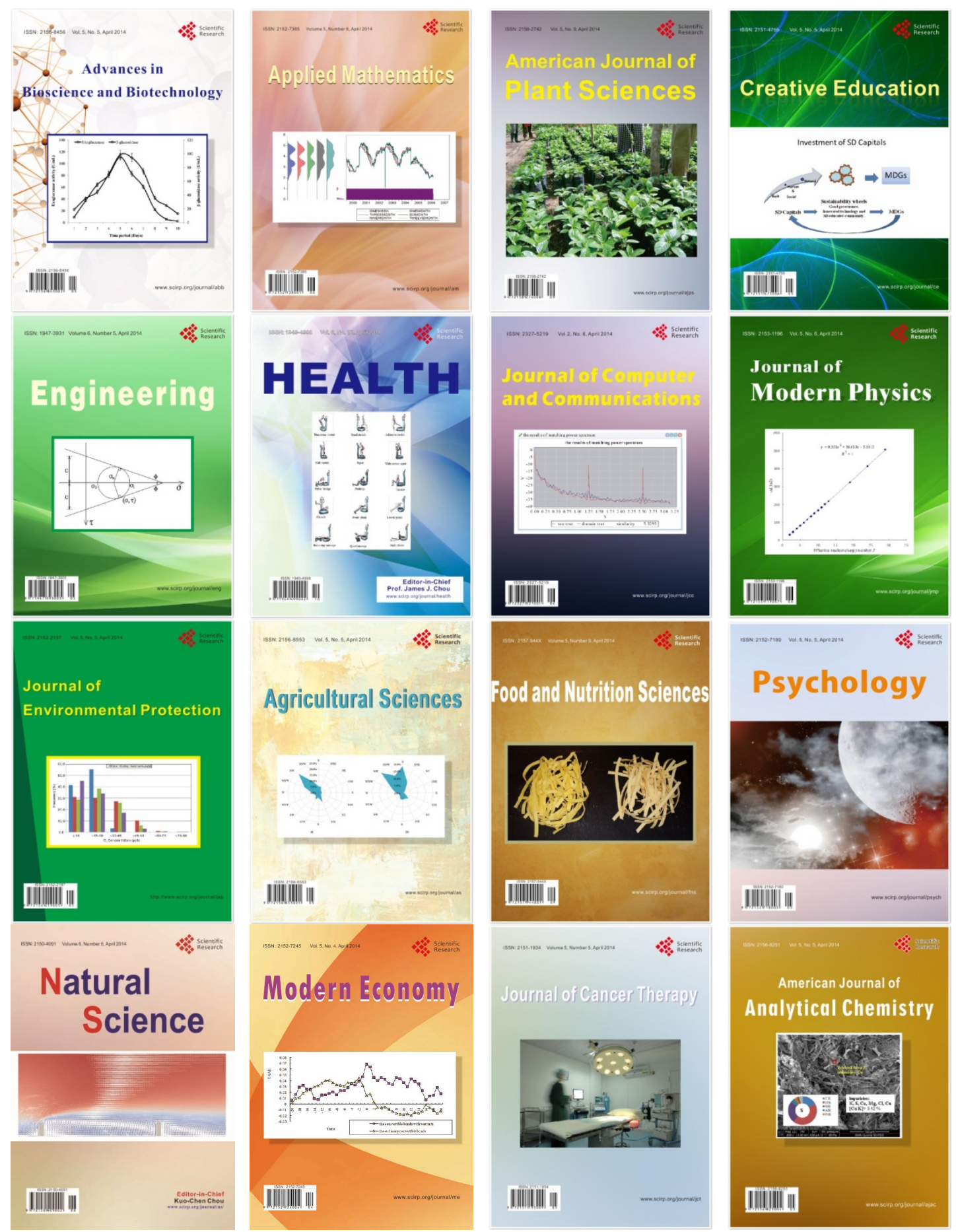